\title{
Effects of Dried Ginger Ethanol Extract on Gluten Sensitivity
}

\author{
Shin-Ae Kim' , Jin-Woo Kim², Soo-Cheol Choi ', In-Ah Lee ${ }^{1}$, and Yong-Wook Shin ${ }^{2}$ * \\ 'Department of Chemistry, College of Natural Science, Kunsan National University, Gunsan, Jeollabuk-do 54150, South Korea \\ ${ }^{2}$ Department of Agronomy \& Medicinal Plant Resources, Gyeongnam national University of Science and Technology, Jinju 52725, South \\ Korea
}

\begin{abstract}
In this study, we used dried ginger ethanol extracts which had been used for alleviation of pain and antipyretics for a long time, and confirmed anti-inflammatory and anti-oxidative activities among various pharmacological actions of dried ginger. The result of antioxidant activity using DPPH (1,1-diphenyl-2-picrylhydrazyl) free radical scavenging activity, dried ginger shows concentration-dependent radical scavenging activity and more than $80 \%$ radical scavenging activity at concentration of dried ginger above $1 \mathrm{mg} / \mathrm{ml}$. Also, in the mouse experiment in which gluten intolerance was induced by providing gluten meal, the effect of inhibiting weight loss was confirmed comparing administrated gluten group and dried ginger administration group. In addition, IL-4, an allergic cytokine, was measured in the small intestine and serum using ELISA (enzyme-linked immunosorbent assay), the results showed that IL-4 production in the dried ginger administration group was significantly reduced compared with the administered gluten 200 $\mathrm{mg} / \mathrm{ml}$ group. In case of IL- 6 and TNF- $\alpha$ production, which are inflammatory cytokines, decreased in the primary culture cell treated with lipopolysaccharide (LPS) for induction of inflammation after treatment with dried ginger in a dose-dependent manner. As a result, it was confirmed that the dried ginger extract has a high antioxidant activity and has a mitigating effect on the gluten intolerance which is an inflammatory allergic reaction.
\end{abstract}

Keywords: anti-allergic effect, anti-inflammatory effect, anti-oxidant, gluten intolerance, immune enhancement

\section{Introduction}

As people's interest in natural foods has grown, research on their ingredients has been actively conducted, and efforts to develop functional materials using nutrients contained in natural foods have increased. The efficacy of these natural foods have long been proven, and thus they have been used in oriental medicine. Earlier studies show that they have anti-oxidant, anti-inflammatory and anti-allergic effects, and improve immunity. Ginger (Zingiber officinale Rosc.), native to Asia, is a perennial herb of Zingiberaceae grown in subtropical or tropical regions (Kim and Choi, 1998). As ginger has a unique flavor and scent, it is widely used in Korea as a spice in Kimchi, Jeotgal (salted seafood) and snacks in various forms such as fresh ginger, dried ginger, ginger extracts and ginger oil (absolute, oleoresin) (Kim et al., 1991). In oriental medicine, ginger is used to reduce indigestion, vomiting, diarrhea and pain and improve blood circulation, and it also has anti-inflammatory effects (Lee et al., 2012). It was also reported that ginger has multiple bioactive effects

This study was funded by the "2017 Anti-aging industry promoting support project" by GNTP.

Received: November 15, 2017, Revised: December 21, 2017, Accepted: December 21, 2017

First author: Shin-Ae Kim, E-mail: ksina16@kunsan.ac.kr, ORCID: 0000-0002-6500-4702

*Comresponding author: Yong-Wook Shin, E-mail: ywsynn@gntech.ac.kr, ORCID: 0000-0002-4983-0107

C) 2018 by the Society for People, Plants, and Environment. This is an Open Access article distributed under the terms of the Creative Commons Attribution Non-Commercial License (http://creativecommons.org/licenses/by-nc/4.0/) which permits unrestricted non-commercial use, distribution, and reproduction in any medium, provided the original work is properly cited 
including anti-bacterial, anti-inflammatory, anti-oxidant and anticarcinogenic effects (Sheo, 1999; Thomson et al., 2002; Stoilova et al., 2007; Shukla and Singh, 2007). In particular, 6-gingerol, one of the spicy substances of ginger has anti-inflammatory, anti-oxidant and disinfecting effects, and reduce serum cholesterol levels (Lee and Ahn, 1985; Cooksley, 1996). In addition, oleoresin, gingerol, and shogaol in ginger activate the function of natural killer cells (NK cells), and improve immunocompetence (Zakaria-Rungkat et al., 2003). Ginger water and ethanol extracts increase the proliferation of splenocytes and the cytokine production of peritoneal macrophages in in-vitro experiments, and thus improve immunity (Ryu and Kim, 2004).

An allergy is an excessive reaction by the immune system to foreign substances or external environmental stimuli, causing hives, rhinitis and asthma. In particular, allergies to foods have increased in Korea recently, and they are an instant reaction to allergens in foods (Han et al., 2012). To avoid the side effects of the existing anti-allergic drugs, such as steroid or antihistaminic agents, functional foods that contain widely-used natural substances that were proven to be effective for allergy treatment and safe for the long-term use need to be utilized in treating allergies (Yoon et al., 2015).

Gluten, a protein complex contained in wheat and barley, increases the chewiness of bread, and it is composed of gliadin monomers ( $\alpha$-, $\beta$-, $\gamma$ - and $\omega$ - types), and disulfide-bond glutenin polymers of high and low molecular sub-units (Wieser, 2007). Gluten acts as an allergen in the body and it increases the maturity of bone marrow-derived dendritic cells (DC), and activates helper T-cells. At the same time, it increases the proliferation of B-cells and induces humoral immunity, and this excessive immune reaction caused by gluten is called gluten sensitivity (Shan et al., 2002). Gluten sensitivity is a systemic immune reaction that results in various symptoms, and it is a hereditary factor that shows an abnormal immune reaction to the intake of gluten (Brandtzaeg, 2002). Earlier studies on gluten sensitivity mostly focused on gastrointestinal disease symptoms. However, gluten sensitivity observed on the skin (dermatitis herpetiformis) and the nervous system (gluten motor disorders, gluten neuropathy) shows that gluten sensitivity is not limited to gastrointestinal symptoms, and studies on exogenous symptoms without gastrointestinal symptoms have been conducted recently (Sapone et al., 2012).

To examine the effects of dried ginger on the reduction of gluten sensitivity, an in-vivo experiment was conducted on a gluten sensitivity-induced mouse animal model by inducing an allergic reaction to gluten in the small intestine in this study.

\section{Methods}

\section{Samples and experimental animals}

Ginger used in this study was supplied from Sancheong-gun, South Gyeongnam Province, and ginger samples were stored in a refrigerator at $4^{\circ} \mathrm{C}$ before using it. Animals used in this study were 4-week old male ICR mice (Orient Ltd., Sungnamsi, Korea) and they were used after 7 days of the acclimation process. The indoor temperature and relative humidity of the breeding rooms were maintained at $23 \pm 1{ }^{\circ} \mathrm{C}$ and $60 \pm 5 \%$ respectively, and the cycle of light and darkness was 12 hours. Feed and water were supplied unlimitedly. in vivo Mice were divided into 5 groups as follows: the normal control group, the G100 control group orally administered with $100 \mathrm{mg} / \mathrm{kg}$ of gluten, the G200 control group orally administered with $200 \mathrm{mg} / \mathrm{kg}$ of gluten, the Dg50 group orally administered with $100 \mathrm{mg} / \mathrm{kg}$ of gluten and $50 \mathrm{mg} / \mathrm{kg}$ of dried ginger simultaneously, and the Dg100 group orally administered with $100 \mathrm{mg} / \mathrm{kg}$ of gluten, and $100 \mathrm{mg} / \mathrm{kg}$ of dried ginger simultaneously, and 7 mice were assigned to each group (Table 1). To the normal control group, the same volume of sterile distilled water was orally administered. Their weight was measured at the same time everyday. They were fasted for 12 hours on the last day of breeding, and they were sacrificed using the cervical dislocation method. Their small 
Table 1. The scheme of in vivo study.

\begin{tabular}{ll}
\hline Group & \multicolumn{1}{c}{ Details } \\
\hline Nor & No treatment \\
G100 & Gluten $100 \mathrm{mg} / \mathrm{kg}$ \\
G200 & Gluten $200 \mathrm{mg} / \mathrm{kg}$ \\
Dg50 & Gluten $100 \mathrm{mg} / \mathrm{kg}+$ dried ginger $50 \mathrm{mg} / \mathrm{kg}$ \\
Dg100 & Gluten $100 \mathrm{mg} / \mathrm{kg}+$ dried ginger $100 \mathrm{mg} / \mathrm{kg}$ \\
\hline
\end{tabular}

intestine was removed and a blood sample was taken from the heart under anesthesia with chloroform. All the samples were stored at $-20^{\circ} \mathrm{C}$ for later analysis.

\section{Reagents}

Cell culture reagents including fetal bovine serum, RPMI 1640 media and antibiotics were purchased from Gibco BRL (Grand Island, USA), and Tris-HCl and LPS were purchased from Fisher Scientific (Hampton, VA, USA). Anti-oxidant activity was tested using ethanol and L-ascorbic acid purchased from SAMCHUN Chemical (Gyeonggi, Korea), and DPPH (1,1-diphenyl- 2-picrylhydrazyl) purchased from SIGMA (St.Louis, USA). The ELISA test was conducted using the IL-4 ELISA kit, IL-6 ELISA kit and TNF- $\alpha$ kit of Younginfrontier (Seoul, Korea), and the absorbance of samples was measured using a micro plate reader produced by Fisher Scientific (Hampton, VA, USA).

\section{Anti-oxidant test by measuring DPPH radical scavenging activity}

The anti-oxidant effect of a dried ginger extract was tested by measuring the electron donating ability of samples using a 1,1-diphenyl-2-picrylhydrazyl (DPPH) radical scavenging method. To do so, a dried ginger extract of $100 \mu 1$ at 0.1-10 $\mathrm{mg} / \mathrm{ml}$ was dissolved in $70 \%$ ethanol, and the mixed solution of $0.2 \mathrm{mM} \mathrm{DPPH} 100 \mu \mathrm{l}$ was reacted in a darkroom for 20 minutes. Its absorbance was measured using a microplate reader at $520 \mathrm{~nm}$. The results were compared with the negative control group not added with the solution, and the free radical scavenging activity was expressed as a percentage. Ascorbic acid, a widely used antioxidant, was used for the positive control groups. The anti-oxidant test was measured 3 times and the mean value was used for analysis. The percentage formula for electron donating ability is as follows:

Electron donating ability $(\%)=\{1-(\mathrm{A}-\mathrm{B}) / \mathrm{C}\} \times 100$
A: sample absorbance $520 \mathrm{~nm}$
B: color control absorbance $520 \mathrm{~nm}$ (without DPPH)
C: negative control absorbance $520 \mathrm{~nm}$ (without sample)

\section{Changes in the number of intestinal bacteria}

To identify the effects of dried ginger on the suppression of the transfer of inflammation caused by gluten sensitivity, the excreta of animals of each group was collected three times in total on the first day, after one week and on the last day. The collected excreta was homogenized in a sterilized $1 \times$ PBS, and $50 \mu 1$ of a 104 times diluted sample using $1 \times$ PBS was smeared on a solid medium, and was cultured in a culture medium at $37^{\circ} \mathrm{C}$ for 24 hours. After that, colonies were counted and expressed as $\mathrm{CFU} / \mathrm{ml}$. 


\section{Measurement of working memory using a Y-maze}

The working memory of mice was measured using a Y-maze. The behavioral test using the Y-maze was conducted on each mouse under a dark environment for 6 minutes (Gong and Choi, 2016).

\section{Analysis of spontaneous alternation behaviors}

A spontaneous alternation behavior is a behavior that an animal chooses a new path after exploring one path (Olton and Samuelson, 1976). There were 6 spontaneous alternation cases including ABC, ACB, BAC, BCA, CAB and CBA. Based on the results of analyzing the behaviors of each mouse, the number of visits to paths and the number of spontaneous alternations were measured and the spontaneous alternation behavior percentage was calculated as follows:

Spontaneous alternation behavior $(\%)=$ The number of spontaneous alternations $\times 100 /$ (the number of visits -2 )

\section{Development of the entropy and analysis of behaviors using an algorithm}

The value of 6 spontaneous paths was divided by the number of potential spontaneous alternations (the total number of visits to paths-2) and the result was used as a Pi value.

Entropy $=\Sigma \mathrm{PilogPi}$

The entropy was calculated using the equation above, and the mean value of each group was compared with each other.

\section{Measurement of allergic cytokine (IL-4)}

The collected blood samples were centrifuged at $4^{\circ} \mathrm{C}$ at $4000 \mathrm{rpm}$ for 10 minutes to separate the serum from the blood. Approximately $5 \mathrm{~cm}$ of the small intestine from the end was removed, treated with a lysis buffer, and homogenized using a homogenizer. After that, it was centrifuged at $4^{\circ} \mathrm{C}$ at $8000 \mathrm{rpm}$ for 10 minutes 3 times. The supernatant was collected and quantified using the enzyme-linked immunosorbent assay (ELISA) method. The ELISA kit used in this study was the Mouse IL-4 ELISA kit purchased from Younginfrontier (Seoul, Korea), and the test was conducted according to the guidelines of the producer.

\section{Measurement of inflammatory cytokines (IL-6, TNF- $\alpha$ )}

To examine the effects of dried ginger on the creation of inflammatory cytokines when inflammation occurs in LPS-induced primary culture cells, the levels of inflammatory cytokines were measured using the ELISA method. Cells extracted from the brain, spleen, and large intestine of mice were plated on a $24-$ well plate by $1 \times 10^{6}$ cell/well, and cultured in a 5\% CO2 incubator for 2 hours. The cells were stimulated with LPS $(1 \mu \mathrm{g} / \mathrm{ml})$, and, at the same time, treated with dried ginger $(1,2,5,10 \mathrm{mg} / \mathrm{ml})$. After that, the cells were cultured for 24 hours additionally. The inflammatory mediators of proinflammatory cytokines were quantified using the supernatant of cells and an enzyme-linked immunosorbent assay (ELISA). The ELISA kit used in this study was the IL-6, TNF- $\alpha$ Mouse ELISA kit purchased from Younginfrontier (Seoul, Korea), and the test was conducted according to the guidelines of the producer.

\section{Measurement of the level of nitric oxide (NO)}

The level of nitrite in a culture medium was measured using the Griess reaction (Yee et al., 2000). RAW 264.7 cells were plated on a 24 -well plate by $1.0 \times 10^{6}$ cells/well, and cultured in a $5 \% \mathrm{CO} 2$ incubator for 20 hours. The cells were 
treated with the dried ginger extract $(0.1,0.25,0.50,1 \mathrm{mg} / \mathrm{ml})$, stimulated with $1 \mu \mathrm{g} / \mathrm{ml}$ of LPS, and cultured for 24 hours. After that, the cells were centrifuged at $4^{\circ} \mathrm{C}$ at 2,000 rpm for 10 minutes, and the concentration and absorbance of $\mathrm{NO}$ produced in the cultured medium were measured at $540 \mathrm{~nm}$ using a NO kit (Thermo Fisher Scientific Inc.).

\section{Statistical analysis}

All the tests were repeated over 3 times, and the mean value \pm SD (standard deviation) of each item was calculated. Using the student's t-test, the statistical significance of the results was evaluated (reliability level $=95 \%(p<.05))$.

\section{Results and Discussion}

\section{Measurement of DPPH radical scavenging activity}

DPPH radical scavenging activity is measured using the principle that deep purple colored stable DPPH free radicals turn into a pale color as they are reduced by an antioxidant, and the method is relatively simple and useful to measure the anti-oxidant activity of various samples (Huang et al., 2005). To examine the anti-oxidant effect of dried ginger, electron donating ability was measured using the 1,1-diphenyl- 2-picrylhydrazyl (DPPH) radical scavenging method, and the results are as shown in Fig. 1. The scavenging activity at the concentration of $0.1 \mathrm{mg} / \mathrm{ml}$ and $0.5 \mathrm{mg} / \mathrm{ml}$ was $53.39 \%$ and $77.33 \%$ respectively, and that at the concentration of $1 \mathrm{mg} / \mathrm{ml}$ and $2 \mathrm{mg} / \mathrm{ml}$ was $84.53 \%$ and $88.56 \%$ respectively. The scavenging activity at the concentration of $4 \mathrm{mg} / \mathrm{ml}$ and $6 \mathrm{mg} / \mathrm{ml}$ was $87.08 \%$ and $87.71 \%$ respectively, and that at the concentration of $8 \mathrm{mg} / \mathrm{ml}$ and $10 \mathrm{mg} / \mathrm{ml}$ was $86.86 \%$ and $91.74 \%$ respectively. The results show that the higher the concentration, the higher the scavenging activity. Ascorbic acid was not dependent on concentrations and showed the scavenging activity of $89.60 \sim 92.20 \%$. When the concentration of dried ginger was higher than $8 \mathrm{mg} / \mathrm{ml}$, the anti-oxidant activity level at ascorbic acid $0.1 \mathrm{mg} / \mathrm{ml}$ was observed.

\section{Changes in weight}

The effects of dried ginger on the weight of mice that is reduced due to gluten sensitivity were examined using a gluten sensitivity-induced mouse experiment (Fig. 2). From the first day of the experiment, gluten was administered, and the weight of the G100 and G200 groups decreased until the ninth day of the experiment due to gluten sensitivity. The weight of the Dg50 and Dg100 groups decreased until the sixth and third day of the experiment respectively, and after that the

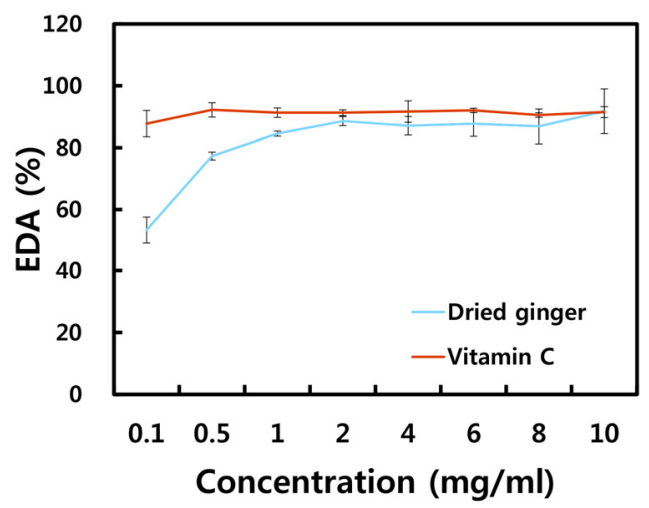

Figure 1. DPPH radical scavenging activity of dried ginger extracts. Data represent the mean \pm SD with three separate experiments. 


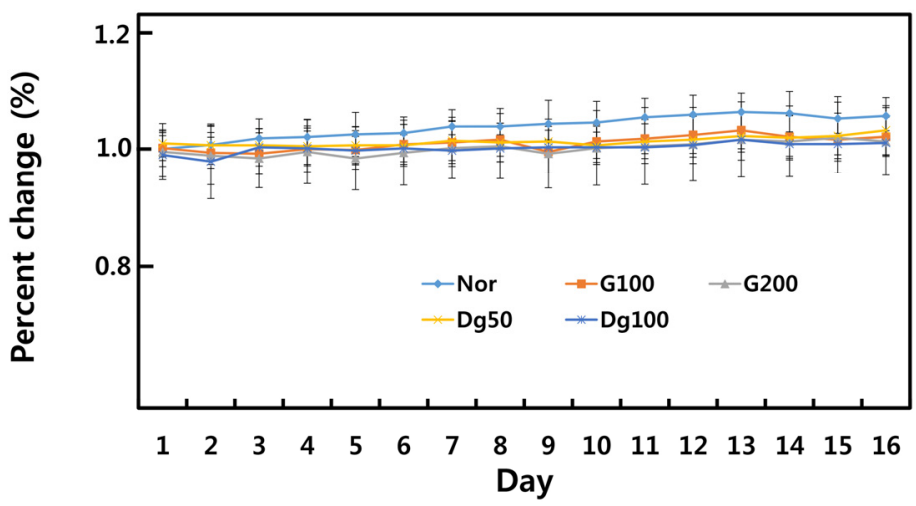

Figure 2. Percent change in body weight over time. Data represent the mean \pm SD with three separate experiments.

weight had slightly increased, which indicates that the administration of dried ginger suppressed the reduction of the weight of mice caused by gluten sensitivity.

\section{Measurement of working memory using a Y-maze}

Gluten sensitivity is a systemic autoimmune disease with various symptoms, and affects not only the intestines but also the nervous system, causing anxiety, allergic reaction, depression, emotional ups and downs, attention-deficit hyperactivity disorder (ADHD), difficulties in concentration, cerebellar atrophy, etc. (Fasano and Catassi, 2001). Therefore, to evaluate the working memory of gluten sensitivity-induced mice, a Y-maze test was conducted (Fig. 3). First, the spontaneous alternation behavior of mice was measured, and the behavior of the G200 group was statistically significantly lower than that of the normal control group (Fig. 3A). The spontaneous alternation behavior percentage of the groups administered
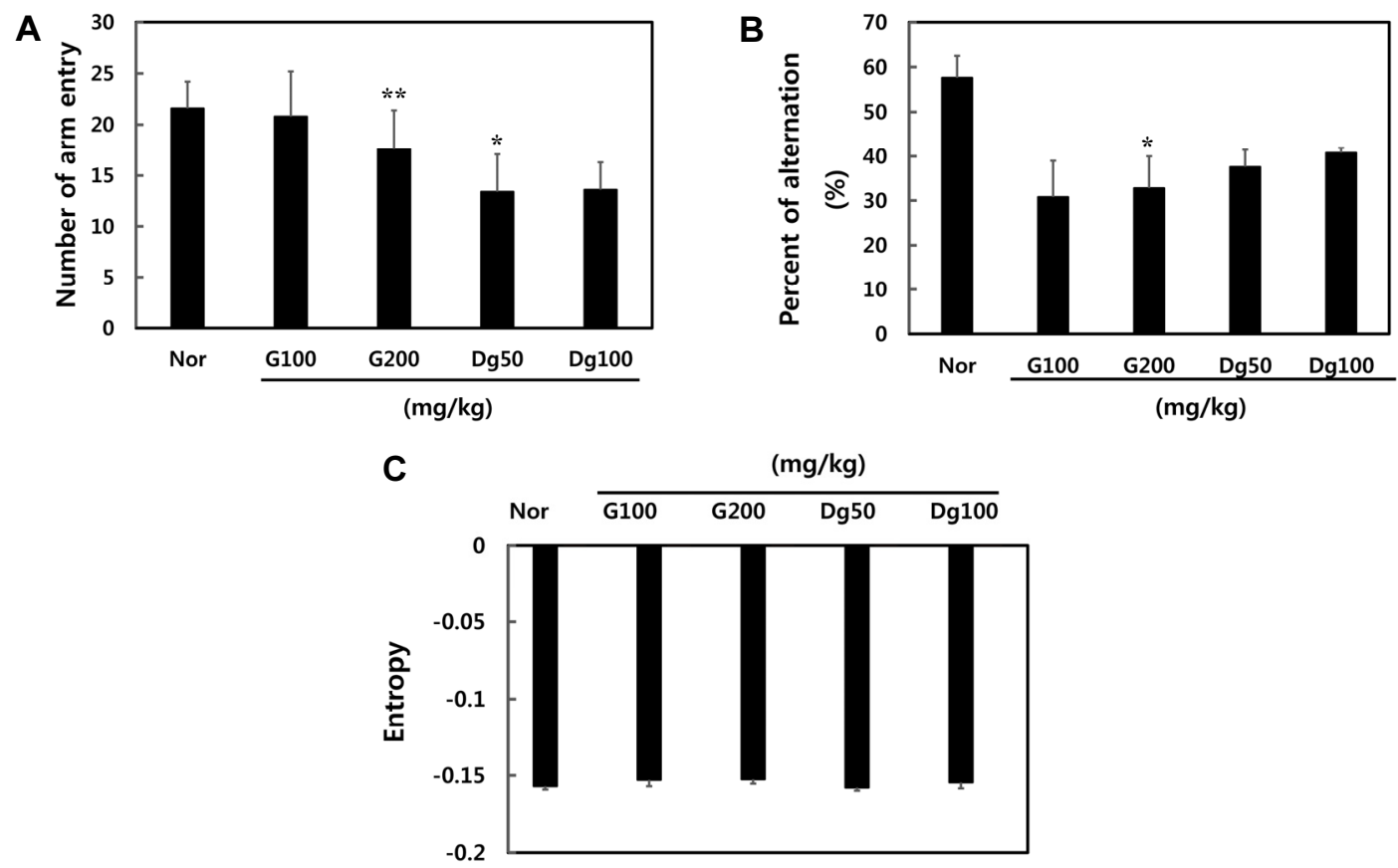

Figure 3. Statistical analysis of working memory in mice. (A) Working memory behavior on Y maze recorded for 6 min (B) The percent of alternation (C) The entropy. Data were represented as mean \pm SEM (Significant as compared to control. $* p<.05, * * p<.01)$. 
with dried ginger was $10 \%$ higher than that of the control groups administered with gluten only. The entropy results using the algorithm mentioned above did not show any statistically significant difference between groups. The results indicate that the administration of dried ginger was effective to suppress the reduction of working memory caused by gluten sensitivity.

\section{Changes in the number of intestinal bacteria}

To examine the transfer of inflammatory reactions caused by gluten sensitivity, the number of intestinal bacteria in the excreta of mice was counted (Fig. 4). The experiment was conducted for two weeks, and the number of intestinal bacteria was measured on the first day, after one week and on the last day. The total number of intestinal bacteria of the inflammation-induced groups using gluten sensitivity was statistically significantly higher than that of the normal control group, and the total number of intestinal bacteria of the inflammation-induced groups showed a statistically significant increase on the last day of the experiment compared to that of the normal control group. The CFU/ml value of the groups administered with dried ginger decreased after one week of the experiment, and increased on the last day, but the growth rate was lower than that of the groups administered with gluten only.

\section{Measurement of allergic cytokine (IL-4)}

The levels of IL-4 in the small intestine and serum of allergy-induced mice using gluten are as shown in Fig. 5. The level of IL-4 in the small intestine in the G100 and G200 groups was $19.82 \%$ and $61.67 \%$ of that of the normal control group respectively. The level of IL-4 of the Dg50 and Dg100 groups showed a statistically significant decrease depending

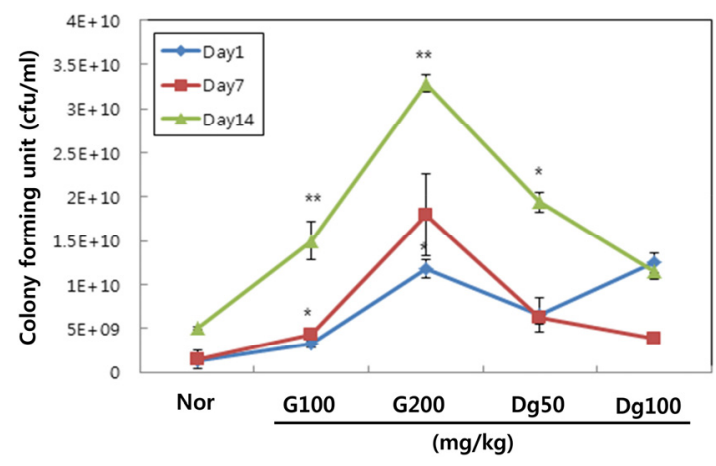

Figure 4. Changes in total bacteria count. Data represent the mean \pm SD with three separate experiments (Significant as compared to control. $* p<.05, * * p<.01)$.
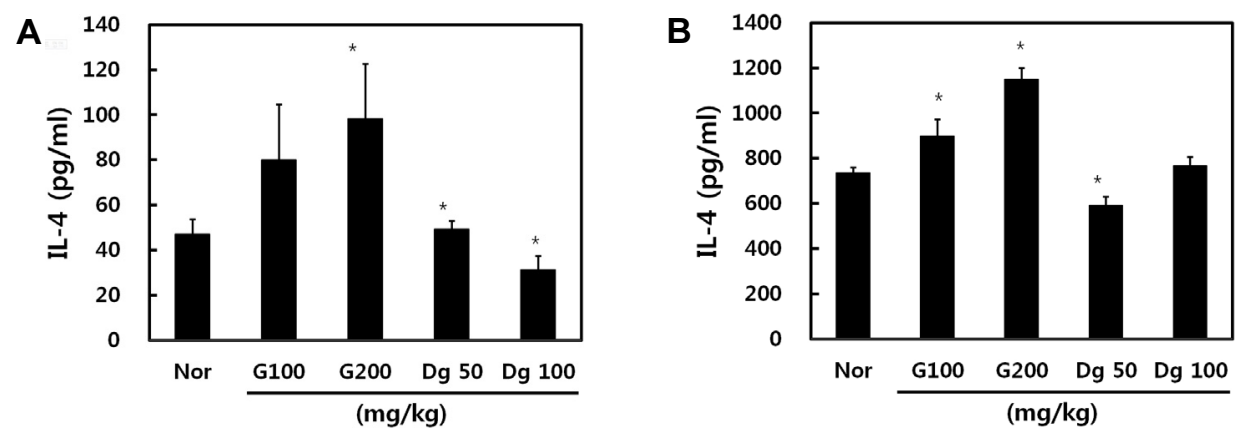

Figure 5. Quantification of IL-4. (A) small bowel tissue (B) serum. Data represent the mean \pm SD with three separate experiments (Significant as compared to control. $* p<.05, * * p<.01$ ). 
on the concentration of dried ginger. The level of IL-4 in the serum in the groups administered with gluten showed a statistically significant increase, and that in the groups administered with dried ginger was lower than that in the groups administered with gluten only. However, there was no difference between groups administered with the different concentrations of dried ginger. These results indicate that the administration of dried ginger was effective to reduce the level of IL-4 produced by allergic reactions caused by gluten.

\section{Measurement of proinflammatory cytokine (TNF- $\alpha$ )}

TNF- $\alpha$, a protein produced by activated macrophages, is combined with the TNFR of other immune cells during inflammatory reactions and increases the expression of inflammatory mediators (Tracey et al., 2008). To examine the effects of dried ginger on macrophages of the brain, large intestine and spleen of inflammation-induced mice using LPS (1 $\mu \mathrm{g} / \mathrm{ml}$ ), the level of TNF- $\alpha$ was measured as shown in Fig. 6 . The groups treated with LPS showed a higher TNF- $\alpha$ level than the normal group, and the level of TNF- $\alpha$ in the brain cells of the groups administered with dried ginger decreased depending on the concentration of dried ginger, showing no statistically significant difference. The level of TNF- $\alpha$ in the cells of the large intestine was statistically significantly reduced in the groups administered with $1,2 \mathrm{and} 5 \mathrm{mg} / \mathrm{ml}$ of dried ginger. The level of TNF- $\alpha$ in the cells of the spleen of the groups treated with LPS only was the highest, and the level of TNF- $\alpha$ in the groups administered with dried ginger showed a statistically significant decrease depending on the concentration of the dried ginger ethanol extract. It was found that the dried ginger ethanol extract was effective to suppress the creation of TNF- $\alpha$ in the cells of inflammation-induced mice using LPS ( $1 \mu \mathrm{g} / \mathrm{ml})$.

A

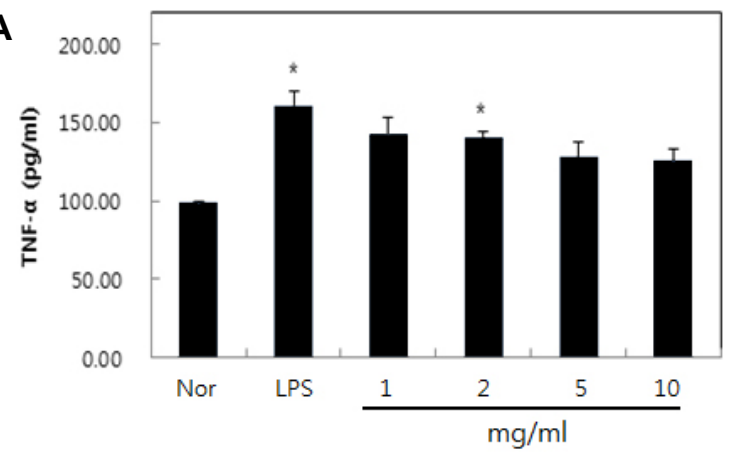

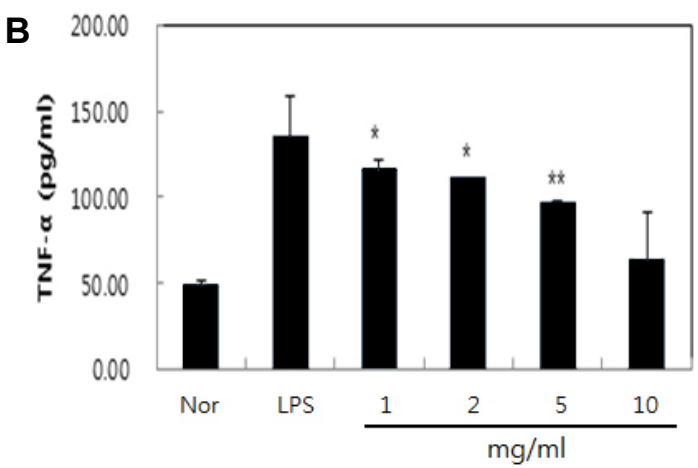

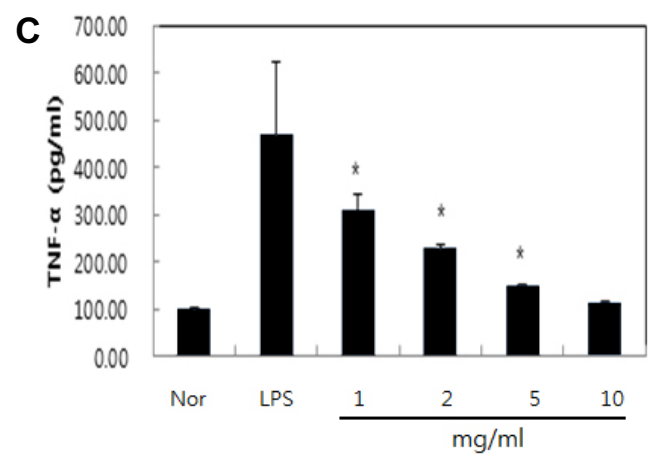

Figure 6. Effects of dried ginger on the production of TNF- $\alpha$ stimulated by LPS. (A) Brain cells (B) large bowel cells (C) spleen cells. The Production of was measured in the medium of cells cultured with LPS $(1 \mu \mathrm{g} / \mathrm{ml})$. The amount of TNF- $\alpha$ was measured by ELISA as described in materials and methods. Nor : LPS not induced group, LPS : LPS induced group. Data represent the mean \pm SD with three separate experiments (Significant as compared to control. $\star p<.05, * * p<.01)$. 


\section{Measurement of proinflammatory cytokine (IL-6)}

IL-6 activates lymphocytes related to acquired immunity as it is combined with an IL-6 receptor (Gabay, 2006). Changes in the level of IL-6 produced in the brain cells of inflammation-induced mice using LPS (1 $\mu \mathrm{g} / \mathrm{ml})$ after administering dried ginger were measured as shown in Fig. 7. The level of IL-6 in the groups treated with LPS was higher than that of IL-6 in the normal control group, and the level in the groups administered with the dried ginger ethanol extract was reduced depending on its concentration. However, there was no statistically significant difference. Changes in the level of IL-6 depending on the concentration of the dried ginger ethanol extract were analyzed, and it was found that the dried ginger ethanol extract was effective to suppress the creation of IL-6 in the cells of inflammation-induced mice using LPS $(1 \mu \mathrm{g} / \mathrm{ml})$.

\section{Effects on the suppression of the creation of nitric oxide}

Nitric oxide (NO) is a diatomic free radical that shows a strong reaction, and an important substance involved in physiological or pathologic reactions in the body. The proper level of NO regulates immunity and dilates blood vessels, but the excessive level of $\mathrm{NO}$ accelerates inflammatory reactions and causes pathologic reactions such as bronchitis and multiple sclerosis and immune disorders (Kim et al., 2012). To examine the effects of the dried ginger ethanol extract on

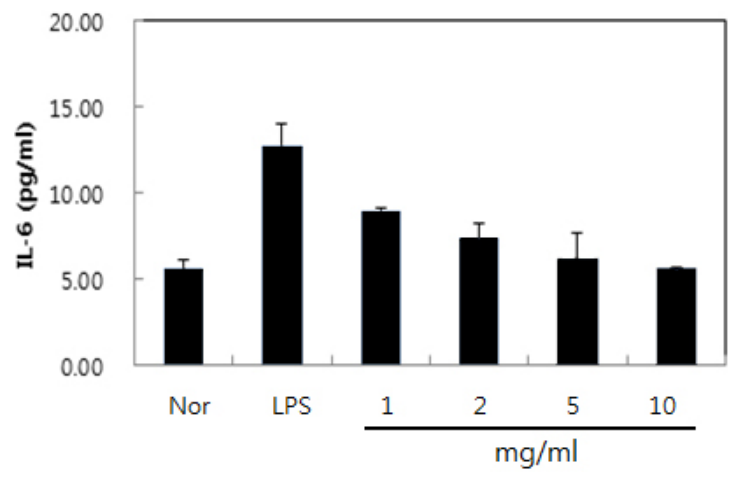

Figure 7. Effects of dried ginger on the production of cytokines stimulated by LPS. Production of IL-6 was measured in the medium of brain cells cultured with LPS $(1 \mu \mathrm{g} / \mathrm{ml})$. The amount of IL-6 was measured by ELISA as described in materials and methods. Nor: LPS not induced group, LPS : LPS induced group. Data represent the mean \pm SD with three separate experiments (Significant as compared to control. * $*<.05, * * p<.01$ ).

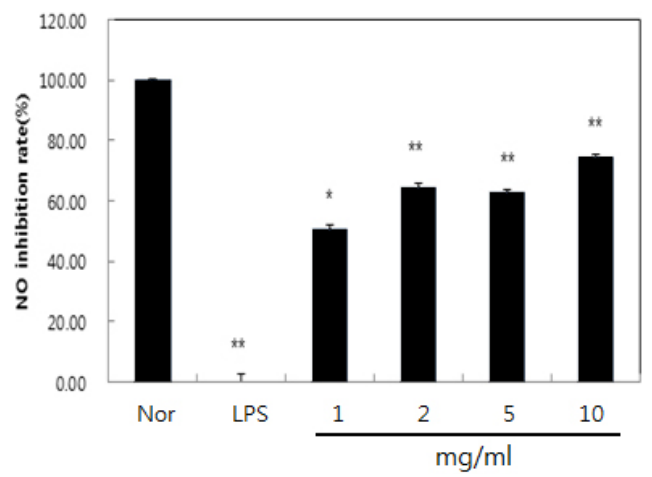

Figure 8. Effect of dried ginger extracts on nitric oxide production in RAW 264.7 cells. Cells were incubated in the treatment of LPS $(1 \mu \mathrm{g} / \mathrm{mL})$ alone or in combination with D. japonica extracts $(0.1,0.25,0.5$, and $1 \mathrm{mg} / \mathrm{mL})$ for $24 \mathrm{~h}$. The culture media of the treated cells were used to measure NO levels. Data represent the mean \pm SD with three separate experiments (Significant as compared to control. $* p<.05, * * p<.01$ ). 
the suppression of the creation of NO, the level of NO in the RAW 264.7 cells of inflammation-induced mice using LPS was measured using a Griess reagent. Compared to the groups treated with LPS only, the groups administered with the dried ginger ethanol extract statistically significantly suppressed the creation of NO depending on the concentration of the extract. These results indicate that the dried ginger ethanol extract was effective to suppress the creation of NO in macrophages induced using LPS (Fig. 8).

\section{Conclusions}

This study examined the anti-allergic and anti-inflammatory effects of a dried ginger ethanol extract on anti-oxidant activity and gluten sensitivity. The results of analyzing DPPH radical scavenging activity showed that the dried ginger ethanol extract increases anti-oxidant activity depending on the concentration of the extract. It was found that the administration of the dried ginger ethanol extract is effective to suppress the reduction of weight caused by gluten intolerance. In addition, the results of evaluating the spontaneous alternation behavior of mice to measure their working memory using a Y-maze showed that the administration of the dried ginger ethanol extract is effective to suppress the reduction of working memory caused by gluten sensitivity. To examine the transfer of inflammatory reactions caused by gluten sensitivity, the number of intestinal bacteria in the excreta of mice was observed, and the results showed that the $\mathrm{CFU} / \mathrm{ml}$ growth rate of the groups administered with the dried ginger ethanol extract was lower than that of the groups administered with gluten only. In addition, the level of IL-4, an allergic cytokine created by immune reactions which were caused by gluten, in the small intestine and serum of mice was measured, and it was found that the administration of the dried ginger ethanol extract is effective to reduce the creation of IL-4 by allergic reactions caused by gluten. Based on the results of earlier studies that substances that can regulate the creation of inflammatory cytokines including TNF- $\alpha$ and IL- 6 can be used as a therapeutic agent for chronic inflammation and autoimmune diseases, the effects of the dried ginger ethanol extract on the activity of macrophages in the cells of inflammation-induced mice using LPS were examined by measuring the levels of TNF- $\alpha$ and IL-6. The results showed that all the groups showed a statistically significant decrease in the levels of TNF- $\alpha$ and IL- 6 depending on the concentration of the extract, and that the extract is effective to suppress the creation of NO caused by inflammatory reactions in macrophages induced using LPS. These results are attributable to the anti-inflammatory effects of dried ginger. Therefore, it can be concluded that the dried ginger ethanol extract is effective to reduce allergic reactions and inflammation caused by foods, and thus that the extract can be used as a food allergy relief medicine.

\section{References}

Brandtzaeg, P. 2002. Current understanding of gastrointestinal immunoregulation and its relation to food allergy. Ann N.Y. Acad. Sci. 964:13-45. DOI:10.1111/j.1749-6632.2002.tb04131.x

Cooksley, V.G. 1996. Aromatherapy: a lifetime guide to healing with essential oils (pp.349-350). Upper Saddle River, NJ, USA: Prentice Hall.

Fasano, A. and C. Catassi. 2001. Current approaches to diagnosis and treatment of celiac disease: An evolving spectrum. Gastroenterology 120(3):636-651. DOI:10.1053/gast.2001.22123

Gabay, C. 2006. Interleukin-6 and chronic inflammation. Arthritis Res. Ther. 8(Suppl 2):S3. DOI: 10.1186/ar1917

Gong, D.Y. and Y.S. Choi. 2016. Development of New Analytical Method Evaluating Working Memory on Y Maze. J. Life Sci. 26(2):234-240. DOI:10.5352/JLS.2016.26.2.234

Han, Y., J. Kim, and K. Ahn. 2012. Food allergy. Korean. J. Pediatr. 55:153-158. DOI: 10.3345/kjp.2012.55.5.153 
Kim, J.S., M.S. Koh, Y.H. Kim, M.K. Kim, and J.S. Hong. 1991. Volatile flavor components of Korean ginger (Zingiber officinale Roscoe). Korean J. Food Sci. Technol. 23(2):141-149.

Kim W.J. and H.S. Choi. 1998. Natural Spices (pp.53-70). Seoul, Korea: Hyoilbooks Co.

Kim, Y.S., S.J. Lee, J.W. Hwang, E.H. Kim, P.J. Park, and J.H. Jeong. 2012. Anti-inflammatory effects of extracts from Ligustrum ovalifolium H. leaves on RAW264.7 macrophages. J. Korean Soc. Food Sci. Nutr. 41(9):1205-1210. DOI:10.3746/jkfn.2012.41.9.1205

Lee, H.M., K.T. Kim, and K.H. Lee. 2012. Quality characteristics of ginger (Zingiber officinale Roscoe) as the ripening periods. J. Food Hyg. Saf. 27(4):479-486. DOI:10.13103/JFHS.2012.27.4.479

Lee L.K. and S.Y. Ahn. 1985. The antioxidant activity of gingerol. Korean J. Food. Sci. Technol. 17(2):55-59.

Olton, D.S. and R.J. Samuelson. 1976. Remembrance of places passed: spatial memory in rats. J. Exp. Psychol. Anim. Behav. Process. 2(2):97-116. DOI:10.1037/0097-7403.2.2.97

Huang, D., B. Ou, and R.L. Prior. 2005. REVIEWS: The Chemistry behind Antioxidant Capacity Assays. J. Agric. Food Chem. 53(6):1841-1856. DOI:10.1021/jf030723c

Ryu, H.S. and H.S. Kim. 2004. Effect of Zingiber Officinale Roscoe Extracts on Mice Immune Cell Activation. Korean J. Nutr. 37(1):23-30.

Sapone, A., J.C. Bai, C. Ciacci, J. Dolinsek, P.H. Green, M. Hadjivassiliou, K. Kaukinen, K. Rostami, D.S. Sanders, W. Schumann, R. Ullrich, D. Villalta, U.Volta, C. Catassi, and A. Fasano. 2012. Spectrum of gluten-related disorders: consensus on new nomenclature and classification. BMC Medicine. 10:13. DOI: 10.1186/1741-7015-10-13

Shan, L., Ø. Molberg, I. Parrot, F. Hausch, F. Filiz, G.M. Gray, L.M. Sollid, and C. Khosla. 2002. Structural Basis for Gluten Intolerance in Celiac Sprue. Science 297:2275-2279. DOI:10.1126/science.1074129

Sheo, H.J. 1999. The antibacterial action of garlic, onion, ginger and red pepper juice. J. Korean Soc. Food Sci. Nutr. 28(1):94-99.

Shukla, Y. and M. Singh. 2007. Cancer preventive properties of ginger: a brief review. Food Chem. Toxicol. 45(5):683-690. DOI:10.1016/j.fct.2006.11.002

Stoilova, I., A. Krastanov, A. Stoyanova, P. Denev, and S. Gargova. 2007. Antioxidant activity of a ginger extract (Zingiber officinale). Food Chem. 102(3):764-770. DOI:10.1016/j.foodchem.2006.06.023

Thomson, M., K.K. Al-Qattan, S.M. Al-Sawan, M.A. Alnageeb., I. Khan, and M. Ali. 2002. The use of ginger (Zingiber officinale Rosc.) as a potential anti-inflammatory and antithrombotic agent. Prostaglandins. Leukot. Essent. Fatty Acids. 67(6):475-478. DOI:10.1054/plef.2002.0441

Tracey, D., L. Klareskog, E.H. Sasso, J.G. Salfeld, and P.P. Tak. 2008. Tumor necrosis factor antagonist mechanisms of action: a comprehensive review. Pharmacol. Ther. 117(2):244-279. DOI:10.1016/j.pharmthera.2007.10.001

Wieser, H. 2007. Chemistry of gluten proteins, Food Microbiol. 24(2):115-119. DOI:10.1016/j.fm.2006. 07.004

Yee, S.T., Y.R. Jeong, M.H. Ha, S.H. Kim, M.W. Byun, and S.K Jo. 2000. Induction of nitric oxide and TNF- $\alpha$ by herbal plant extracts in mouse macrophages. J. Korean Soc. Food Sci. Nutr. 29:342-348.

Yoon, H.J., H.S. Shin, S.Y. Hwang, B.H. Yand, and D.H. Shon. 2015. Status of Technology Development for Functional Food Coping with Allergy. Food Sci. Ind. 48(1):38-49.

Zakaria-Rungkat, F., Nurahman, E. Prangdimurt, and Tejasari. 2003. Antioxidant and immunoenhancement activities of ginger (Zingiber officinale Roscoe) extracts and compounds in vitro and in vivo mouse and human system. Nutraceuticals \& Food 8(1):96-104. DOI:10.3746/jfn.2003.8.1.096 